\title{
GrimeiseN, G.
}

Math. Zeitschr. 80, 466 (1963)

\section{Berichtigung}

zu der Arbeit von Gerhard Grimeisen : „Topologisierung R-topologischer Verbände.“ Math. Zeitschr. 80, 239-248 (1962)

Auf Seite 241, Zeile 4 v. o., ersetze man

$$
\text { "} \varphi \leqq " \text { durch }, \varphi \leqq \psi . " .
$$

G. Grimeisen, 7 Stuttgart W, Reinsburgstr. 114 